\title{
Sobre la fillosofía del racismo en el Perú
}

\author{
Fernando Bobbio Rosas \\ Departamento Académico de Filosofía
}

Con profundo respeto

a la memoria de A.S.B.

\section{CULTURA, RELIGIÓN E IDEOLOGÍA}

Cultura es la forma o manera de vivir de los grupos humanos; y así como en el análisis de los individuos se pueden distinguir anatomía y fisiología, lo mismo hallamos en el caso de las culturas. Hay una anatomía (que va de las pirámides a los alfileres y que es el material que estudia el arqueólogo en el caso de las culturas muertas) y una fisiología, que es el funcionamiento de una sociedad. Pero un organismo (individual o social) no es sólo anatomía y fisiología; hay algo que determina, rige u orienta sus acciones, actividades y funciones, todo ello obedece a un programa que es el fundamento de la vida, tanto en que ella es impisiblè sitn él conioeñ que anatomía y fisiología sólo son la manifestación o exteriorización de un programa ${ }^{1}$.

1 Ludwig von Bertalanffy, Concepción biológica del cosmos. Santiago de Chile, 1963, esp. Cc. 2 y 4 .

İd., Teoria general de los sistemas. México, FCE, 1976, cc. V, VI y VIII. Irenäus Eibl-Eibesfeldt, El hombre preprogramado. Madrid, 1977, 1a. y 4a. ptes.

H.S. Jennings, Bases biológicas de la naturaleza humana. Buenos Aires, 1942, cc. XIV$\mathrm{XV}$.

Jacques Monod, El azar y la necesidad. Barcelona, 1971, c. II.

E.S. Russell, La finalidad de las actividades orgánicas. Buenos Aires, 1948.

Erwin Schrodinger, What is life? Cambridge, 1945, c. II.

C.H. Waddington, La naturaleza de la vida. Madrid, 1963.

L.L. Whyte, Internal Factors in Evolution. London, 1965, c. I.

D'Arcy W. Thompson, On Form and Growth. Cambridge, 1942. 
En 1945, luego de una durísima lucha que en su terrible fase final duró poco más de un lustro, se decidió el dominio del mundo. En 1948, luego de un lustro de muy profundas meditaciones ${ }^{2}$, un premio Nobel alumbra la definición de la cultura, 'cultura = df. religión': "la cultura y... la religión de un pueblo, no son aspectos diferentes del mismo objeto;... la cultura [es] la encarnación... de la religión de un pueblo"3. Agrega que la cultura europea es cristiana y que el cristianismo es la religión más verdadera (y la variante inglesa de dicho credo es el non plus ultra de la verdad). Por ello, la cultura europea (específicamente la inglesa) es la superior o, si se quiere, es la cultura. (Por cierto que con gran benevolencia también se puede ampliar el sentido de la palabra y, aún más, se podría conceder que en alguno que otro detalle sin importancia, alguna "cultura" no cristiana pueda ser superior"). No se menciona el fait accompli, que la cultura europea ya estableció, de modo indiscutible, su superioridad (la oligarquía angloyanqui ya se adueñó del planeta); pero en 1948, la mauvaise conscience todavía puede murmurar: "Si desaparece el cristianismo, desaparece toda nuestra cultura"s. (Medio siglo después del proceso, como todos los de degradación, es ya casi irreversible, sólo falta la ejecución de algunos detalles para la globalización).

Pero identificar cultura y religión es tomar la pars pro toto. Pensemos en una Madonna de Botticelli, eso no es religión, se podría aceptar que sin las creencias religiosas del autor el cuadrono existiría, pero esto sólo significa que esa pintura es el gut put de un programa que podría llamarse religión (aunque la religión nada tengaque ver con su calidad de chef-d'oeuvre). Pero

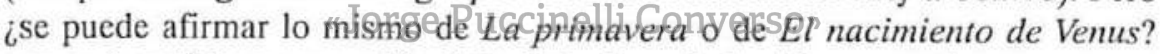
¿en qué medida es expresión del cristianismo holandés un cuadro que retrata putas y borrachos en una taberna? Se puede llamar religión al programa que subyace todas las actividades y todas las creaciones humanas; pero no es correcto, hay varios otros nombres más apropiados: visión o concepción del mundo, Weltanschauung, ideología o, si se quiere, filosofía.

Ahora bien, el programa, tanto en el individuo como en la sociedad, tiene varios niveles y en el más primitivo, el más profundo, yacen sus elemen-

2 T.S. Eliot, Notas para la definición de la cultura. Buenos Aires, 1949, p. 11.

3 Íd., p. 40.

4 İd., p. 48.

5 Íd., p. 197. 


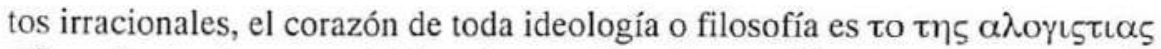
ๆ̛̃os. Pero esto no es totalmente negativo; lo que sí lo es que, como ya lo sabía la Musa Jonia, el V̛́uos nunca pierde ${ }^{6}$ y, muchas veces, tampoco pierde la nefasta úßpıs (de allí la extrema urgencia con que nos ordena aplastarla implacablemente ${ }^{7}$ ). Nada impide llamar 'religión' a ese núcleo de irracionalidad (con sus aspectos negativos y positivos, quizá sea el más adecuado de los rótulos) pero, nuevamente, es sólo parte de una totalidad mayor.

\section{CULTURA Y CULTURAS}

Una de las tantas falsedades tendenciosas aún vigente habla de las "culturas nacionales" (soporte de las "identidades nacionales"); habría una cultura peruana y una cultura boliviana, lo mismo que una francesa y otra española. Cierto, en el más lato de los sentidos, incluso puede hablarse de la cultura humana; pero, stricto sensu, no existen las pretendidas culturas nacionales, ni siquiera en el continente de la cultura de las nacionalidades (de odios y rencores y opresiones seculares) donde/algunos grupos han dispuesto hasta de quince siglos (496 el prime rey merovingio) para ir destruyendo las culturas de sus vecinos y poder absorberlos. La madre patria de muchos "peruanos" es un ejemplo patético de este proceso, cuando hace más de cinco siglos Isabel y Fernando unificaron sus "predios", éste estaba condenando al millón de aragoneses aser aplastados por los gcho millones de hijosdalgo castellanos; pero el regionalismo o separatismo cătalan no es el único, muchos otros pueblos, dueños "de sendas editturas soportan "sq" yugo de Madrid. El último intento de aliviar en algo esta situación desembocó en una feroz carnicería que duró tres años (1936-9) donde se asesinaron un buen par de millones de personas, y varios millones más terminaron como desplazados o refugiados; a esto siguió una terrible represión que duró varios lustros más; así se mantuvo la "unidad" y la monarquía que ahora es "propiedad" de los herederos "legítimos" del caudillo.

En América, el panorama es muchísimo más complejo pese a que las atrocidades perpetradas aquí para, previa destrucción de las culturas autóctonas, imponer la de los conquistadores, han sido mucho más horrendas. En algunos

\footnotetext{
6 Fr. 85 .

, Fr. 43.
} 
lugares donde el genocidio fue absoluto (como en las islas caribeñas donde no quedó un solo nativo vivo) y en otros, donde se puede afirmar que prácticamente también se consumó (cuando la población indígena superviviente es insuficiente para mantener su legado cultural), el resultado no ha sido un cultivo sano, sino culturas enfermas

\section{LA CULTURA "PERUANA"}

El Perú ocupa la mayor parte, la central y la más rica, de lo que fue el Tahuantinsuyu, especie de confederación de culturas afines más o menos voluntaria y más o menos laxamente unificados por su propia conveniencia. Cuando los españoles llegaron a América su principal afán fue destruir las culturas que encontraron (sería imitados, y con mayor éxito por otros europeos). El método más fácil de alcanzar esa meta es el exterminio de las poblaciones nativas y es lo que hicieron cuando les fue posible.

En el Tahuantinsuyu, para imponer esa religión de paz y amor que es el cristianismo, el cura Valverde apretó el detonador de un proceso en el cual, en poco más de un siglo, fueron asesinados entre diez y doce millones de indígenas; por supuesto que no todos esos asesinatos fueron perpetrados directamente (como el complemento gramatical, los asesinatos también pueden ser indirectos o cirepurtangiales) zete esoeno disminuye la fuerza "persuasiva” de tan épica hazaña cometida per tap cristianos caballeros. Pero quizá esa masacre no fue lo más espantoso; lo realmente abominable fue la esclavitud que por más de cuatro siglos estuvieron condenados a sufrir los descendientes de los supervivientes de la Conquista. ( $Y$ no se trata d'épater les bourgeois porque si bien el Perú, desde 1821, es una república soberana y democrática, con sucesivas constituciones que han garantizado la igualdad de sus ciudadanos, hasta hace muy poco podían ocurrir cosas como ésta que menciona Henri Favre: "En 1958, un hacendado de Lircay hizo mutilar a uno de sus trabajadores porque le había "faltado el respeto"... no se había arrodillado delante de él ni le había besado la mano"8).

B Cit. por J.M. Arguedas, Obras completas. Lima, 1983, t. 2, p. 66. 


\section{LOS ROSTROS DEL PERÚ}

Así como el Perú es, desde 1821, una república, desde el siglo XVI la cultura "peruana" es europea o, más exactamente, una prolongación, proyección o deyección de esa cultura. Desde el inca comentador hasta su historiógrafo oficial, toda la "inteligencia peruana" parte de una perspectiva europea y emplea métodos, categorías, normas, patrones, criterios y valoraciones europeos; esto es lo que está admitiendo Riva-Agüero cuando escribe que las cultura española y portuguesa "debemos considerarlas como propias" (El prolífico L.H. Delgado, crítico feroz de Riva-Agüero que, entre otras cosas, objeta su afrancesamiento, admite compartir el mismo vicio: "mi formación intelectual la debo a Francia", "mi patria espiritual") ${ }^{10}$.

Desde otro campo de la inteligencia peruana, el arquitecto Harth-Terré afirma: "nuestra cultura es secularmente occidental, nace del renacimiento español" (El ilustre arquitecto no se refiere a ninguna cultura occidental, la china o la hindú, por ejemplo; la cultura que tiene en mente es la europea que, con la africana, son las culturas orientales o las del este ${ }^{12}$ ).

Como de toda tara fatal, jamás podremos librarnos de ésta europeísmo que vicia incluso la obra de quienes con mayor agudeza, claridad, profundidad e intensidad han pensado y sentido al Perú: José Carlos Mariátegui y Augusto Salazar Bondyiblioteca de Letras

\section{"Jorge Puccinelli Converso"}

Pero para captar la realidad humana, quizá más importante que la literatura científica o filosófica sea la cuentística o novelística; Alain resalta la importancia del testimonio del novelista: "He aprendido en Balzac más que en los filósofos o políticos"13. (Lo mismo se puede decir de Proust o Céline).

$9 \quad$ Obras completas. Lima, 1964, t. III, p. 163.

10 Olavide y Melgar. Lima, 1972, pp. 161 y 163.

"Cit. por Aldo Giovanni Facho Dede, Los cien primeros años de arquitectura republicana en Lima, 1821-1921. Tesis para optar el título profesional de arquitecto. Lima, UNI, 2000, p. 93

12 Fernando Bobbio Rosas, "Dos fraudes intelectuales: la cultura 'occidental' y la 'lengua española"” (inédito).

13 Con Balzac. Buenos Aires, 1948, p. 60. 
Coincidiendo con esta valoración, Arguedas, el menos contaminado por la cultura europea de todos los intelectuales peruanos (Guamán Poma es caso aparte) prefiere el relato novelesco para filmar un Perú que no tiene nada que ver con esa novelita rosa que es la "historia" oficial que ignora la espantosa explotación a que, hasta 1969, estuvo sometida casi toda la población indígena en beneficio de un puñado de gentes que (discrepamos con Carlos Malpica S.S.) no eran Los dueños del Perú, porque desde el siglo XVI los dueños del Perú viven allende sus fronteras y aquí son sus delegados o administradores los que velan por sus intereses. (La Revolución de Velasco ha sido el único intento emancipatorio que llegó al poder pero, desde sus inicios, fue torpedeada y abiertamente traicionada en cuanto se pudo; en 1980 , los borbones fueron restaurados y se les devolvió todo lo que se pudo de "sus" antiguos business. Lo que sigue está muy cerca para ser enjuiciado sine ira et studio.)

Ciro Alegría, Arturo Hernández o C.E. Zavaleta presentan otros aspectos de este cosido (no tan cosido y de ningún modo cocido) que es el Perú. Y el más grande poeta castellano (la tragédia de la España agonizante, que ya murió y no es un decir, amigo César, inspiro una de las más conmovedoras creaciones de este siglo) esboza un cuadrito ("Paco Yunque") y un mural ( $E l$ tungsteno) de esta realidad multifacética. Pero la prosa literaria es urbana par excellence y, desde el Satiricón hasta el Ulysses y La palabra del mudo, barriobajera; ése es el ambiente en el gue se desenvuelven las obras de Ribeyro, Congrains o Renoso que presentan con un realismo insuperable la patética indefensión (1a mưdez) del marginadoyerbano, objeto y no sujeto de la maquinaria social (esta situación propia de la cultura europea ya está globalizada de Buenos Aires a Nueva Delhi y de Londres a Tokio).

Pero tampoco se puede confinar la literatura al arrabal o al albañal; la literatura europea medieval es caballeresca y cortesana (quizá no pudo haber sido de otro modo). Y si el mayor crédito de la prosa castellana reposa en el Quijote y en la novela picaresca, muy poco después, el más kolossal de los testigos, relatores, notarios y fedatarios nos revela las minucias de la más sofisticada y poderosa corte cristiana en la más exquisita de las prosas europeas. En el siglo pasado, al lado de Los miserables y de los impactantes cuadros de Zola, La comédie de Balzac es la de la llamada clase media. Y, a diferencia de Kafka o de Joyce, para revolucionar la literatura de este siglo, Proust toma sus materiales de salones cuyos habitúes pretenden seguir actuando sous l'ancien régime. 
En el Perú, Palma recorre varios de sus nichos ecológicos, mostrando una gran predilección por el virreinato (de donde proceden varios cientos de sus "tradiciones" frente a sólo media docena de relatos de la época prehispánica) $\mathrm{y}$ por sus pisos altos con su desfile de esclavos y obispos, virreyes y mercachifles, oidores y cortesanas que simbolizan el Perú oficial que constituye una continuidad sin rupturas; en 1821 se marchó el virrey pero quedó todo lo demás.

En la segunda mitad de este siglo, un muy leal súbdito de sus muy católicas majestades los reyes de todas las Españas inicia su carrera literaria narrando algunos de los avatares de su vida de interno en un colegio de jóvenes provenientes de hogares pobres o muy pobres dando especial énfasis a los desahogos eróticos de sus ardientes condiscípulos; por ejemplo, recuerda con cierta delectación las expediciones burdelescas de sus compañeros o las "violaciones" de que hacen objeto a la Malpapeada (las otras, mejor no meneallas) y maltrata con mucha bajeza a un pobre profesor homosexual que, aparte del cuasi delito de ser profesor y del conexo e imperdonable crimen de ser pobre, es una de las figuras del párnaso castellano (¿de esas aguas no beberé?).

Pero muy pronto el propio Varguitas está relatando "el despichulamiento de Pichula de Cuéllar" ya en un colegio de clase media/alta con un lujo de detalles que envidiaría cualquier testigo y, por último, encarna en el hijastro elogiador alumno del santa maría cuando ta plutocracia peruasna desasnaba

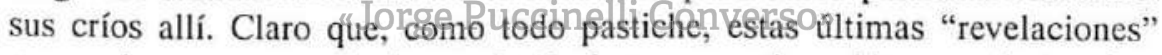
suenan huecas, pese a la depurada técnica con que han sido manufacturados. (Por lo demás, esa técnica es la clave de su éxito comercial y éste, el de su "encumbramiento": de contemplar los pies desnudos del Jaguar y aspirar sus efluvios, "ascendió" a admirar calzados regios y aspirar los aromas celestiales que emanan de los cuerpos reales ${ }^{14}$ ).

\section{ESA LIMA EN INGLÉS, ENVIDIOSA DE MIAMI}

Muy poco después del bang de Varguitas, uno de esos babies born with a silver spoon in his mouth (aunque la plutocracia born in America solía usar

14 "El intelectual entre la rebelión y la sumisión: Vallejo y Varguitas en España". 
la plata para sus orinales) desciende de su penthouse para exhibir (y explotar) las vivencias de su infancia dorada (incluidas carroza y banda presidenciales arrumadas entre los trastos): Un mundo para Julius.

Y, apenas ayer, llevado de la manita ya no por su mamama como en Los últimos días de La prensa, sino por el más vendido de los literatos castellanos, Bayly se integra al team del boom. Pero no es accidental que los exponentes de la Lima miamita sean mister Bryce and mister Bayly, como tampoco lo es que "el hombre más rico del Perú" que tanto impresionara a Yimito sea míster Canock, por más que se trate de un apellido ficticio; esto es lo "natural" en esta sociedad desnaturalizada donde sería raro que el hombre mas rico apellidase Androide (el vecino de Yimito en el cerrito), Manrique o Pérez, pese a que son apellidos tan europeos como los otros; y donde lo inconcebible sería que Quispe o Huamán llegasen a ser los más ricos del país. (En 1066, un grupo de asaltantes capitaneados por Guillermo 'El Bastardo' se apoderó de Inglaterra y sometió a la población indígena a esa esclavitud que los historiadores llaman servidumbre; huego sus descendientes se apoderaron de Escocia e Irlanda. Hasta el siglo pasado la situación de los proletarios de las islas era casi equiparable a la del mujik ruso y apenas 'mejor' que la de las grandes masas de los desposeídos del resto del mundo, lo que provoca la reacción no sólo de los novelistas, que siempre han sido el termómetro de la sociedad, sino la elaboración de la teoria marxista. En la primera mitad de este siglo, su estado continuó siendo deplorable, como se aprecia, por ejemplo, en Afuera y abajo de George Orwell, todavia, novecientos años después de la conquista la mayor párte dé las grándes fortunas inglesas continuará en manos de los descendientes de aquellos asaltantes).

En la presentación del primer libro de Bayly su padrino (literario) afirma que el joven escribidor encarna "la filosofía de la juventud peruana"1s; con menos descaro, el godson circunscribe su nicho: "esa Lima en inglés, envidiosa de Miami en la que yo vivía"16. Ese es el mundo que Bayly va a exhibir; en sus primeros libros, la exposición de la filosofía de esa Lima miamizada palidece frente a las preocupaciones más urgentes de sus héroes, jóvenes homos o drogos que, en medio de su insaciable sed de sexo o drogas, están clamando a gritos por su redención. Lograda ésta, al parecer, y ya cómoda-

15 No se lo digas a nadie.

16 Yo amo a mi mami. Lima, 1998, p. 186. 
mente instalado en la respetabilidad burguesa, el héroe más reciente de Bayly ya puede bucear en su pasado más remoto para arrancarle sus más inocentes vivencias y vendérnoslas; total, the life itself is a business.

Desde la Eva del primer capítulo, arrojada a la calle por los celos estúpidos de la madre, hasta la Manuela de los dos últimos, muerta de agotamiento al pie de su batido, Yo amo a mi mami es una serie de viñetas por las que desfilan quienes cuidaron y protegieron al principillo Yimito dándole no sólo ternura y comprensión, sino también algunos ejemplos de honestidad, laboriosidad o responsabilidad, cualidades muy escasas entre sus padres, parientes o amigos. De todos ellos los dos únicos que despiertan cierta simpatía son el papapa (que no vacila en estafar a la cía. de seg. ${ }^{17}$ ) y el tío revolucionario cuya aparición fugaz impide observarlo bien.

\section{EL RACISMO}

Фúçı, homo sapiens es discriminador y segregacionista; pero la euro-

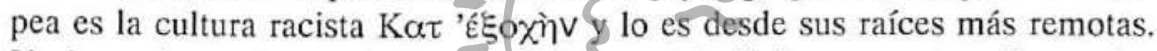
Ya los griegos (como lo harăn los romanos) distinguen entre ellos y los $\beta \alpha \rho \beta \alpha \rho o t$ que, por principio, son inasimilables ${ }^{18}$. Cuando este legado griego se mezcló con el romano y el judío, su perniciosidad se potenció al máximo; el cocktail resultante sejlämő Europa-que, junto con "el árbol de sus razas" que el poeta reclama alborozado, transplanto a esta "América autóctona y salvaje" el bosque de sus prejuicios que ya "hace trescientos años, esplendente florecía// y lleno de memeces, florece todavía".

En el Perú (y en todo este feo remedo de Europa que es América) los prejuicios raciales están tan arraigados y extendidos que funcionan como axiomas; el terrateniente no es el único "convencido hasta la médula, por la acción de los siglos, de su superioridad sobre los indios" 19 , sino que también lo está cualquier blanco, blanquecino o blancuzco. En el medio urbano esta actitud encaja con la de gran parte de la población cholindia desarraigada que se siente inferior y trata de blanquearse. (Por otro lado, cómo puede sentirse

\footnotetext{
17 Íd., p. 142.

18 T.J. Haarhoff, The Stranger at the Gate. Oxford, 1948.

19 J.M. Arguedas, Obras completas, t. I, p. 105.
} 
igual a sus amos, patrones o empleadores el peón o la doméstica a quienes todos tienen "derecho" a maltratar, cuando menos de palabra. Y cuando algunos de estos marginados que descubrieron a new way to make money, eludiendo la morosidad y la inmoralidad tradicionales de los canales oficia$\operatorname{les}^{20}$, fueron arrojados con una ferocidad inédita en nuestra vida urbana la motivación, consciente o no, de este afán de "limpiar la ciudad"21, fue impedirles la posibilidad de escapar a la miseria a que están condenados).

Así pues, discriminación y segregación raciales son algo "natural" y sólo se les presta atención cuando la víctima de alguna manifestación de este tipo es un "personaje"; entonces, el "incidente" rellena algún periodiquillo amarillo, verde o rosa. "Cecilia Tait, un desgarrador testimonio sobre el racismo en el Perú"22 es un ejemplo de este tipo de sensacionalismo barato donde lo más importante no es el "desgarrador" testimonio ceciliano, sino la entrevista a un científico cholindio que cuenta haber salido de una de estas situaciones discriminatorias tomándolo a risa y, por supuesto, obedeciendo; con ello "evité un espectáculo que sólo hubiera conducido a que me golpeen". Esta docilidad hilarante le permite sentirse "siempre por encima de... estos problemas. Que ellos existan nunca me asustó... no existe mejor manera de vivir... que reírse de los tropiezos"23. (Paul Rassinier menciona la sumisión sonriente como una táctica femeninoeuropea: "La hembra siempre se somete riendo a la ley del vencedor..."24; el personaje de la entrevista, como buen científico, la generaliza.)blioteca de Letras

\section{"Jorge Puccinelli Converso"}

El Aléxandros "desată" nudos manu militari y Wittgenstein "disuelve" problemas more philosophico; pero el aporte de este científico made in Peru siglo XX es más profundo, no sólo resuelve problemas y supera tropiezos, sino que ha enriquecido las reglas seculares que rigen la vida de las haciendas peruanas $^{25}$ con el principio de la obediencia risueña. Manes de José María ¿podrás perdonarnos?

21 "Réquiem por la informalidad", Letras, N 94, pp. 59-68. Lima, 1997.

22 Revista Somos del 3 de octubre de 1998, pp. 32-6. Entrevista a Cecilia Tait y Luis Millones.

23 Íd., p. 36.

24 Paul Rassinier, La mentira de Ulises. Barcelona, 1962, p. 40.

25 J.M. Arguedas, Obras completas, t. III, p. 192. (Trabajo, silencio y devoción). En lo sucesivo todas las citas, excepto tres, son de Yo amo a mi mami: 


\section{LA FILOSOFÍA DEL RACISMO}

A falta de estudios "científicos", la otra gran "fuente" para estudiar el racismo en el Perú es la literatura donde, desde la prosa noble y angustiada de Arguedas hasta la de Varguitas y Bayly, el racismo ocupa el primer plano o se relega al trasfondo, repta vergonzante o se yergue descarado; esto es lo que ocurre en los libros de Bayly y, sobre todo en el último donde Yimito exhibe todo, su casa y sus autos, sus sirvientes y sus papis, sus lacoste y sus milkyway y, con el mismo desenfado, el programa que hace funcionar su mundo, la ideología y filosofía (degradando los términos para aplicarlos a ese amasijo de prejuicios, falsedades, supersticiones y simplezas que constituye el bagaje "intelectual") de los ricos peruanos (adoptado por las masas de desarraigados que vegetan en todas las ciudades de estos reinos).

La espina dorsal de esta filosofía es el racismo impuesto aquí desde el siglo XVI; y este racismo se puede resumir en un credo bastante simple:

-Creo que hay dos tipos de gentes ý que nosotros tenemos todas (o casi todas) las virtudes y ellos todos (o casi todos) los vicios o defectos; por eso, nos corresponden todos (o casi todos) los derechos y privilegios y a ellos todos (o casi todos) los deberes y obligaciones. Como el dinero corrompe este rerum ordo, ellos deben ser mantenidos en la pobreza per secula seculorum. Amén.

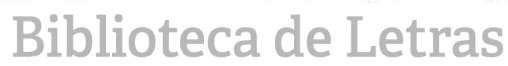

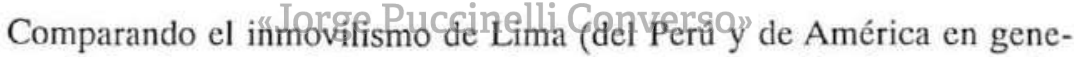
ral) con el de alguna capital europea, la mami da su versión de este credo: "prefiero mi Lima donde la gente sencilla está en su sitio y no se viene a mezclar con nosotros,... qué pasaría si los cholitos en Puno descubrieran pozos de petróleo, sería el acabose, todo el orden natural de las cosas se echaría a perder, vendrían a Lima con sus millones cochinos y se pasearían por nuestro cerrito privilegiado, porque... como dice siempre tu papá, cholo con plata es más peligroso que mono con metralleta"26. Hay pues un ordo naturalis que, sobre todo cuando ambas partes lo respetan, ya ni se siente y que está incluso en las formulaciones más inocentes, como cuando el papapa dice: "todos los seres humanos necesitamos hacer una siestecita"27; implíci-

\footnotetext{
26 p. 398.

27 p. 137.
} 
tamente los sirvientes ya ni siquiera son seres humanos, ellos no hacen siesta, no pueden hacerla porque su tarea es velar por la siestecita de los seres humanos.

\section{FUtURología, TEOLOGÍA Y ÉTICA}

El little speech con que la mami resume la filosofía del racismo revela cierta inquietud por el futuro que en otro lugar expresa más claramente: "la gente sencilla se está reproduciendo demasiado rápido y a veces me aterra que en unos años no quede más gente fina" ${ }^{28}$. Al lado del lenguaje casi interjectivo de la gente fina (cholo ratero ${ }^{29}$, mentiroso como buen serrano ${ }^{30}$, cholerío pestífero ${ }^{31}$ ) el vuelo intelectual de la mami es notable, aunque papi también hace sus aportes: "Mi papi decía que los negros en el Perú han nacido para ser choferes, porteros o futbolistas del Alianza, nunca de la U..."32. Pero la mami gana ampliamente, no sólo se proyecta en el plano terrenal, sino también pontifica sobre lo más alto, como recuerda Yimito que, al morir, quiere ir al cielo con mami, con papi y con la bermanita "y también, si les dejan entrar, con los empleados, aunque ellos según mi mami, vivirían en una zona aparte... un cielo más modesto, como para ellos" ${ }^{33}$. Mientras, preparándolos para el más allá, la mami tiene para los empleados, no un gueto, sino "la chanchería" ${ }^{34}$.

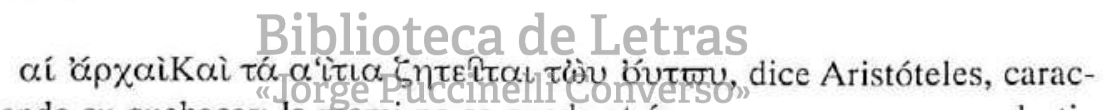
terizando su quehacer; la mami no se queda atrás; pero, con mayor modestia

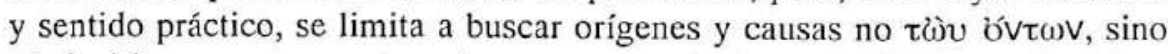

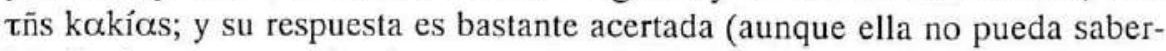
lo): "todo se comenzó a descomponer cuando los negros fueron sacados del África" ${ }^{35}$.

$\begin{array}{ll}{ }_{28}^{28} & \text { p. } 388 . \\ { }_{29} & \text { p. } 197 . \\ { }_{30} & \text { p. } 337 . \\ { }_{31} & \text { p. } 359 . \\ 32 & \text { p. } 308 . \\ 33 & \text { p. } 352 . \\ 34 & \text { p. } 346 . \\ 35 & \text { p. } 236 .\end{array}$ 


\section{DRAMATIS PERSONAE}

¿Quiénes interpretan el guión? De un lado, los "blancos, bien parecidos, de ojos claros y modales refinados" ${ }^{\text {"36; }}$ del otro, la gente simple o sencilla, cholos, "morenos y feúchos" ${ }^{37}$. En realidad, lo principal es tener mucha plata $\mathrm{y}$, simplemente, de ser uno de esos "señores millonarios" que viven en alguno de los enclaves que les proporciona su riqueza malhabida. Yimito pasa una revista impecable e implacable a sus vecinos en ese "cerrito que diosito inventó para la gente como nosotros ${ }^{38}$ ". Empieza con mrs. Zaric, la gorda borracha que, se cree, mató al marido por celos; sigue un exembajador inglés que abandonó el servicio y se quedó en el cerrito para rosquetear como loco (total, también eso sale más barato por aquí). Continúa el vago número 1 del Perú, "tacaño, pingaloca y pichicatero". El siguiente es el gordo Androide, nuevo rico, "un tiburón para hacer plata"; Andrews es algo parecido, ya no a un tiburón, pero sí "una máquina de hacer plata, un gran negociante, su negocio es hacerse el loco"; el ciego Bonilla es el único casi decente de este vecindario tan exclusivo cuya lista cierra- un tal Macri, traficante de armas argentino que, "cuando llegó, era un pobretorn, no tenía donde caerse muerto" ${ }^{39}$. Estos son les elus du bon dieu, la élite peruasna cuya obsesión es hacer plata, "más y más plata, toda la plata del mundo quiere mi papá"40 y sus diversiones fornicar y emborracharse; que no leen porque "leer muchos libros a lo mejor te da algo de cultura, pero po te deja un puto centavo"41, (este agudo filosofema no es madeinperu siglo XX, es la mas auténtica expresión del "espíritu" capitalista. Ya en e1 Sigfo Xiv, Boccaccio se ve obligado a defender los estudios humanísticos "contra el desprecio de los filisteos, ... que afirmaban que ni la literatura, ni el estudio de la poesía eran lucrativos" ${ }^{42}$ ) que se sienten autorizados para robar "porque en fin, se puede robar con
36 p. 189.
37 p. 197.
38 p. 362.
39 pp. 370-374.
$40 \quad$ p. 342.
$41 \quad$ p. 373.
42 Millard Meiss, La pintura en Florencia y Siena después de la peste negra. Madrid, 1988, p. 189.
43 p. 318 . 
dignidad”43 y cuyas dignas señoras esposas están prestas a entregarse al primer fulano que las requiera, siempre que tenga más dinero que su señor marido ${ }^{44}$.

\section{LA PRAXIS}

Obtenida la riqueza se la ostenta del modo más estúpido e insolente; "la tía riquísima y solterona que daba a su perra croissants con mermeladas importadas" 45 agrega maldad a la estupidez de su "cariño" enfermizo por la mascota. Y el interrogatorio a que es sometido el pobretón de Yimito por baby Canock es el colmo de la psicopatología infantil: “Cuántos carros tienen? Tres.- Nosotros cinco y tres camionetas para los cholos... ¿Cuántas empleadas? Cuatro.- Nosotros cinco y una sola para mí... Tengo un closet que vale miles de dólares... No tienes helados Milkyway, ni queso Philadelphia, ni cornflakes importados" ${ }^{\prime 4}$.

Todo esto aplasta a Yimito: "tiene tanta plata que a su lado me quedo calladito y me siento su empleado... lo admiro" ${ }^{47}$. El padre actúa de modo similar, cuando llega el viejo Canock, "mi papi se le acerca presuroso y sonriente como nunca lo he visto" ${ }^{48}$ y la conducta paterna "justifica" la del junior que, para conseguir la amistad de baby Canock, hará "lo que le pida, aparte de que mi papies-asi de sobón con suppapá"s ‘. Pero el pobrecito de Yimito no sólo es maltratado por Canock, también recuerda a ese "rubiecito engreído nos miraba a los peruanos como si fuésemos vicuñas" 50 (evidentemente ignoraba el valor de las vicuñas). Ahora bien, este complejo conductual es natural, desde su aparición en la sociedad más simple (según SchjelderupEbbes, dos gallinas nunca viven juntas sin decidir cual de ellas ha de ser la dominante $^{51}$ ) hasta la mise en scène más versallesca. Por lo mismo, la piadosa

44 pp. $219-220$.

45 p. 174.

46 pp. $212-214$.

47 p. 208.

48 p. 211.

49 p. 216.

so $\quad$ p. 196.

51 David Katz, Animales y hombres. Madrid, 1961, p. 232. 
madre natura nos ha dotado de un espinazo muy flexible (que un antiquísimo proverbio chino agradece a los dioses) y, en el colmo del refinamiento, obedecemos o nos agachamos con la sonrisa a flor de labios.

Esto ocurre entre "los señores millonarios"; al otro lado está, por ejemplo, "Tiburcia, la planchadora quemada... llena de cicatrices vive la pobre por lo mucho que se quema con la plancha" 52 . Pero la prima donna de este submundo es la Manu de quien Yimito recuerda "sus recios olores de mujer sencilla que se lava con jabón para lavar ropa, pues Manu y su ropa se lavan con jabón y así mi mami está feliz porque ahorra unos centavitos y Manu ni se queja porque se resigna con cualquier cosa... y si un día mi mami la vendiese, no por cien, sino por mil soles, porque mami es vivísima para ganarse siempre un dinerillo, Manu aceptaría su suerte sin quejas ni rencores" ${ }^{53}$.

No se queja, no guarda rencor y sonríe la Manu, así "supera" sus problemas, "se contenta con comer las sobras que dejamos para ellos, los empleados" 54 (los postres no sobran ademâs, "la gente de la serranía" 55 no aprecia esas cosas). Luego de la cena y "terminadas sus tareas, en lugar de irse a dormir, tenía que limpiar toda la platería... yo veía a Manu cayéndose de sueño"56; también hay que limpiar la docena de zapatos de la mami, "Manu todas las madrugadas, de cuatro a seis, se dedicaba a limpiar los muchísimos, excesivos zapatos de pil mami, la coobre Manu que sólo tiene un par de zapatillas viejas... por eso cuando mami sale de viaje le recuerdo que le traiga a Manu unas zapatilas nuevas; pero ella se olvida siempre de Manu y de los demás empleados y con las justas les trae de regalo el azuquitar y las mermeladas del avión lo que claro, es más que suficiente para que Manu esté feliz" 57 . Finalmente, la pobre Manu cae al pie de la paila, batiendo el maná, como lo hecho a lo largo de décadas ("mientras el maná se endurece, Manu envejece" 58 podría haber sido el lema de su vida).

\footnotetext{
52 p. 405.

53 pp. 398-399.

54 p. 335 .

55 p. 345 .

56 p. 341 .

57 p. 401.

58 p. 403.
} 


\section{CONSUMATUM EST}

Con todos sus defectos y deficiencias (casi todos impuestos por el sistema) los cholichanchos son los únicos que poseen cierta textura, calor y profundidad humanos. La gente fina está más alienada que sus víctimas; sus valores y sus metas son fatuos, superficiales, deleznables como los que Yimito envidia o admira en su primito: "Yo lo envidiaba, de grande quería ser como él, así tan grande y con esos ojazos azules.", "secretamente, lo admiraba, admiraba su belleza, ..., sus ojazos azules"59. Eso es lo que se aprecia y desea, envidia y admira, el pellejo blanco (blanquecino o blancuzco, aunque sea), la pelambre amarilla (hasta castañita, cuando menos) los ojos claros; tener algunas de estas nobles cualidades da satisfacción y seguridad, el primito tiene esos "ojos celestes, orgullo de la familia"60.

Toda esta tontería podría pasar; lo peor es la obsesión neurótica en conseguir, acumular y despilfarrar el dinero del modo más torpe; para obtenerlo se sienten autorizados a robar y a prostituirse $y$, sin mencionarlo, a asesinar. Cuando el sistema capitalistá de explotación se siente amenazado, recurre con todo descaro a la solución final aunque se trate del hombre (aparentemente) más poderoso del mundo, como ocurrió con el mayor de los pequeños gracos (demasiado grandes para este siglo XX; además respetando el libreto; también se asesinaría al menor); como es natural, en estos casos, los equipos de investigåciôn eriminal más éfieientes del planeta sólo sirven para enturbiar el panorama, aynque sea ah costo de algunos asesinatos más. Pese a todo, el asesinato directo no es el peor, el más terrible es el indirecto, el que ni se admite ni se considera como tal; por ejemplo, las maniobras de los países ricos causantes de las hambrunas con que se asesina a millones de seres humanos de los países más pobres de esta tierra ya globalmente totalmente atormentada.

El dinero sirve para tener la casa, los autos y las mujeres más caras: "Qué ilusión conocer a ... Canock, seguro que tiene un carro mejor que el de mi papi y viene con un montón de guardaespaldas" y, de inmediato, viene la pregunta clave: "papi ¿qué harías si tuvieras toda la plata de Billy Canock?" La respuesta es obvia: "nos iríamos a vivir a Miami, me compraría un yate

\footnotetext{
59 pp. 171 y 174.

60 p. 174.
} 
de lujo y me pasaría la vida navegando por el caribe"61. Ese es el sueño, la meta y la Meca de los ricos latinoamerichanchos. Más que el pelo o los ojos del primito se envidia su way of life, su pasárselas en Miami ${ }^{62}$ yaciendo "bajo el sol mientras nosotros malvivíamos en un país sucio y caótico"63.

Pero, para que los críos nazcan con la consabida teaspoon in their mouths, se precisa poseer cierta cualidad que quizá todos poseamos, pero no todos desarrollamos; baby Canock suele asesinar a los animalillos que encuentra en su vagar sin rumbo, "con el mismo instinto asesino que su padre debe tener para los negocios, le apuntó sin que le tiemble el pulso, disparó y la despedazó" ${ }^{64}$; su señor padre "es la ballena asesina, nadie en el Perú tiene más plata que él" 65 . Cuando ese instinto no ha sido perfeccionado ya no se puede robar con la suficiente "dignidad" y se resbala al último escalón. Por eso, muchos de los viejos condiscípulos de Yimito "están buscados por la policía o muertos por sobredosis" ${ }^{\prime}$.

Esa es la última salida y, objetivamente hablando, no es la peor; además, el contenido apropiado para un recipiente de plata sólo puede ser áureo o argénteo y si por allí hay un maravilloso oro blanco que colma nuestros más prodigiosos sueños... Así terminó el buen primito, se esfumó (no siendo exhibicionista no permitió espectadores para su apoteosis): "Nunca lo encontraron, ni siquiera su cadáver" ${ }^{\prime 6}$.

\section{Biblioteca de Letras}

APÉNDICE: DE LA PSYCOTFERAPIACONEROSAMALASQUCRATIVA

Noé maldice a Cam por haberlo mirado desnudo; Juan Ignacio no sólo ha contemplado (o imaginado) la desnudez de su madre, sino que la ha
61 p. 208.
62 p. 174.
63 p. 172.
64 p. 226.
65 p. 200.
65 p. 189.
67 p. 179 . 
"pintado... calata, con rabo y en poses obscenas"6s. Pero Yimito supera a J.I., desnuda a su madre absoluta, definitivamente (lo más íntimo del ser humano no son sus genitales) la retrata sin ninguna piedad (con esa maliciosa ingenuidad infantil que es la peor de todas) y, culminando su faena, nos vende el retrato, siguiendo el ejemplo de uno de sus amigos que empezó sacando al mercado los desahogos eróticos de su tía y no paró hasta llegar a su madre a la que, sin mencionar su desnudez, nos permite vislumbrarla revolcándose con el padre en el cuarto contiguo (lo peor no es que Klitaimnéstra engañe al viejo Agamémnon, sino que traiciona al joven Oréstes; por ello hay que asesinarla, real o simbólicamente).

Goethe resalta el papel de la madre en la formación del gran hombre; pero todos tenemos madre, también los disminuidos, los frustrados, los amargados (al buen Yimito parece haberle resultado exitosa su kathársis literaria; pero hay otros que, pese a la fortunita conseguida y al consiguiente "ascenso", continúan llenos de odio y rencor que babean en cuanto se les presenta la ocasión). Y si no todos hemos tenido la suerte de ser hijos de Olympia o de Leticia, alegrémonos de no haberlo sido de Klytaimnestra o de Dora, de la bella tía Bea o de la mami arnada y, así, no necesitar asesinar a nuestras madres para obtener un poco de sosiego y, además, si el asesinato es mera y cobardemente literario, algún dinerillo, por supuesto.

El cuento y la novela fienen caíz cautobiggráfica y siempre han servido de válvula de escape para aliviar represiones y complejos, para desechar recuerdos indigeribles, para disfrazar deseos inconfesables y para atenuar sentimientos negativos (miedos, ansiedades, fobias, angustias); la kátharsis original es la del autor que se complementa con la del espectador o lector que capta el mensaje y, sin necesidad de hacerlo plenamente consciente, se identifica con él; sin esto, como ya nos lo enseñó el viejo Aristóteles, no hay obra de arte.

Pero este siglo (y todo hace suponer que el siguiente será peor) en el que un desarrollo científico y tecnológico sin precedentes ha permitido la mayor acumulación de riquezas para destinarla al despilfarro más insensato (que, en los países ricos se incentiva en todos los niveles de la población) mientras que las grandes mayorías de la humanidad aglomeradas en los países 
despojados (donde sólo los pocos ricos pueden ser consumistas, pero lo son con un entusiasmo que compensa la falta de consumo del resto de sus "compatriotas") vegetan en una miseria que sólo les permite la mera supervivencia (de los que no han muerto ya de hambre, frío o de alguna de las secuelas de estas carencias) ha hecho de la literatura (y de cualquier expresión artística porque, velis nolis, el arte está inextricablemente ligado a la sociedad que, conscientemente o no, retrata o refleja directa o indirecta, fiel o inexactamente) casi exclusivamente, una cañería de desagüe.

Esto no significa poner al mismo nivel la obsesión por el tiempo perdido, la ansiedad por el retorno ineludible al lecho penelopesco o la angustia de la espera por el veredicto incomprensible e inexorable con cualquier "cuento" o "novela" que sean, simplemente, la expresión de algún desorden mental. Que Proust o Tennessee Williams hayan sido homosexuales no consagra como literato a cualquier homosexual que se anime a llenar carillas. Pero, y como parte del clima "intelectual" de este siglo, también hay un público neurótico, neurotizado o idiotizado ávido de desnudeces vergonzosas; por ello, cualquier fulano que, hasta hace poco, hublese tenido que pagar para ser escuchado por el psicoanalista (con la remota esperanza de ser curado) ahora se desahoga por escrito y vende sus confesiones u obsesiones que, mientras más escandalosas u obscenas sean, le aseguran una mejor cotización y una mayor difusión. Y, si el escribidor logra el máximo grado literario (el bestsellerato) devendrá, de vulgar monielmakerè a respetable "intelectual" capaz, incluso, de soñar con la presidencja porque, en este "paisucho perdido en la cola del tercer mundo", "cualquier blanquiñoso payason y palabrero puede... [no solamente]... tener un programa de TV"69, sino que, hasta hace muy poco, tenía reservadas las canonjías más lucrativas, empezando por la presidencia de la república. En este aspecto, lo más pintoresco del último año de este siglo $\mathrm{XX}$ ha sido el viaje de un descendiente de virrey a la ciudad del madroño para ventilar sus aspiraciones a ocupar, la hasta hoy, Casa de Pizarro ${ }^{70}$; para exas-

69 Jaime Bayly, La noche es virgen. Barcelona, 1997, pp. 95 y 53.

70. Nota históricoautobiográfica y de actualidad:

En algún momento del gobierno de Velasco, corrió el chisme de que la estatua de Pizarro iba a ser retirada del sitial que le había consagrado el fervoroso patriotismo de muchas generaciones de limeños; esto agudizó el miedo, la pena y el descontento de partidarios y defensores de la democracia, de las instituciones republicanas, de las libertades civiles, de los derechos humanos y de la justicia natural y divina vilmente pisoteada (no sólo se había despojado de sus haciendas a los pobrecitos gamonales, también se había expulsado 
peración de muchos de los "suyos" que confiaban en su madre P(atría) parece que allí se informó al ilustre viajero que desde 1821, la corte de Madrid ya no proveía las vacantes de la sede virreinalícia limeña.

a las transnacionales que tantos beneficios dispensaban al malagradecido pueblo peruano). Cuando el presidente Allende fue asesinado, muchos se sintieron iluminados por un inesperado rayo de luz; hubo misas donde se rogó para que aquí también apareciera un general "patriota" o, de no ser posible, para que viniese una expedición libertadora. Para nuestro oprobio, nuestra vergüenza y nuestro remordimiento, estuvimos entre aquellos alienados.

Pero, sin ningún afán exculpatorio, recordemos: estando aún tibio cl cadáver de Atahualpa que, velis nolis, simbolizaba el del Tahuantinsuyu, "no solamente curacas, sino también gente del común hacian su ingreso multitudinario a Cajamarca para ofrecer sus servicios a los españoles... Pizarro no descansaba recibiendo a los personajes que arribaban para rendirse ante su persona". [Vid. Waldemar Espinoza Soriano, "La caída del Tahuantinsuyu y la resistencia inca", Alma Máter, № 6, pp. 23-40. UNMSM, Lima, 1993]. Allí, en Cajamarca, al calor de ese cadáver gigantesco cuyo dominio total tardaría décadas y sólo se lograría al costo de una docena de millones de indígenas asesinados, en el más desmesurado Holocausto de la historia, se produjo ese maridaje demencial entre Pizarro y Felipillo - Valverde y Paullu, los progenitores del Perí. Como lo dijo don Manuel, "descendemos de los esclavos Huayna Cápaj y de los siervos de fos habsburgos", con la atingencia de que la diferencia entre 'esclavos' y 'siervos' es sólo gramatical y con el pavoroso agravante de que los esclavos, para poder sobrevikir, fueron forzados por los siervos (sus nuevos amos) a traicionar su traditio. Que luego de más de cuatro siglos de las más espantosa esclavitud, los indígenas hayan podido conservar algo de su legado cultural, merece nuestro más profundo reconocimiento y respeto La "emancipación" requirió de dos intervenciones, la argentinochilena y la colombiana (con êt poderío inglés agazapado detrís de ellas). Al advenirnos el suceso máśimpertantecdeilaelidaGepublieaná(porque desde su nacimiento, el Perú sólo maneja sus menudencias; la Historia nos empuja y nos arrastra, nos atropella y nos arrolla, nos asalta y nos aplasta) como es usual, la oligarquía (los que tienen la palabra, recordando nuevamente a Ribeyro) está dividida; y cuando Piérola parece haberla re-unido, "los chilenos antes que Piérola" no es el slogan exclusivo del decano de la prensa amarilla limeña, sino la opinión "respetable" de muchos peruanos "responsables". Desde esta perspectiva (y ¿qué perfil más fiel que éste de nuestra nacionalidad?) cuando pediamos mediadores o salvadores, cuando clamábamos por sanciones o, incluso porque alguien nos hiciese el favor de invadirnos, encarnábamos la más auténtica peruanidad.

Pero tanto la alienación como sus secuelas, el entreguismo y la traición a los intereses de la comunidad nacional, son crímenes imperdonables; mucho más cuando, como ocurrió en nuestro caso, contamos hasta el final con la confianza, la simpatia y los consejos de ASB ( $y$ de nuestro padre que, desde una modesta posición, fue un entusiasta colaborador del proceso revolucionario). A un cuarto de siglo de la muerte del maestro (y a un lustro de la de nuestro padre) recién empezamos a vislumbrar la naturaleza y la magnitud de la tarea asumida por Velasco (y por el más brillante asesor de la única auténtica revolución peruana). Dada nuestra idiosincracia (desdibujados, acomodaticios, timidones) el proyecto estaba destinado al fracaso. En todo caso, Velasco enfermó gravemente (Salazar murió intempestivamente) y esa dolencia ( $y$ quién sabe qué otros estímulos) alentó la valentía de algunos 
generales que depusieron a Velasco. Consumada la traición aleve, el país volvió a su indolencia gris.

En su hábitat natural, los organismos, cuasi/cursores vitai lampada tradunt (en la bella expresión de Lucrecio); en una sociedad humana sana, además de la chispa de la vida, las generaciones se transmiten las brasas del hogar y del altar comunales. En las sociedades enfermas ( $y$ la peor enfermedad es la alienación que la globalización está convirtiendo de epidémica en pandémica) no hay esta entrega regular de la posta; allí la existencia es de vegetar apático y abúlico que, a lo más, es esporádicamente iluminado por algún chispazo que quema algo de la hojarasca que nos cubre, nos pesa y casi nos ahoga; pero también abriga, los chispazos ngs confundeti Q melestạ, dejâtos doftnir en paz; que vengan los

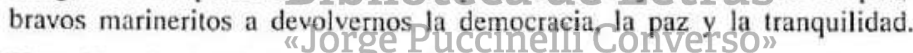

El testimonio de Yimito no sólo tiene valor documental; como todo protocolo fidedigno, puede servir de diagnóstico (sociedad gravemente enferma) y para formular algunos pronósticos. Acabamos de ver en TV (Panorama, 16/07/2000) a algunos de esos jóvenes (cuyas familias han derrochado fortunas para enviarlos a esos negocios, dizque educativos, llamados Santa María, Newton o San Ignacio de Loyola) que, deseando aprovechar al máximo sus periódicos jubileos (son los creyentes más fieles, incapaces de esperar cincuenta años, los realizan cada cincuenta semanas o, incluso, cada cincuenta días) intentaron incursionar en el mundo de los negocios internacionales. Lástima que eligieron mal el producto a exportar; un puñado más de vidas desperdiciado por la desorientación, la incoherencia y la alienación de sus vidas familiares. También escuchamos a un ex ministro que, sin eufemismos, nos hizo conscientes de la presencia en Lima del "virrey Latorre", coincidimos totalmente con el epíteto puesto al personaje de marras, pero su perspectiva es la de la dependencia sonriente; cuando el ministro del país $\mathrm{A}$ es empleado (ex empleado o jubilado, lo mismo da) de un banco del pais B (iquizás el Eat Fango?) A no requiere de virrey; menos aún, si se coloca como presidente de $\mathrm{A}$ a un empleado de alguna de esas cajas de resonancia (bid, oea, fmi, onu) con las que B intenta disimular sus fechorias. El envio de un virrey es, cuando menos, indicio de algún débil intento de no ser totalmente dócil al libreto impuesto; cuando se llega a más, los barcos llegan al golfo pérsico. 


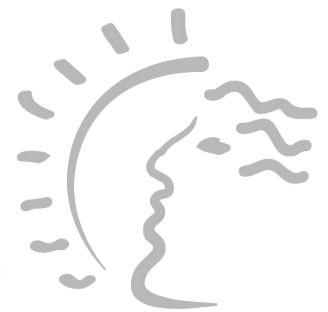

Biblioteca de Letras "Jorge Puccinelli Converso» 